\title{
A Study on the Application of IPA Method for Exploring the Properties of Urban Residents' Choice of Indoor Plants
}

\author{
Na Ra Jeong ${ }^{1 *}$, Kwang Jin Kim², Ji Hye Yoon ${ }^{1}$, Seung Won Han¹, and Soojin You ${ }^{3}$ \\ ${ }^{1}$ Researcher, Urban Agriculture Division, National Institute of Horticultural \& Herbal Science, RDA, Wanju 55365, South Korea \\ ${ }^{2}$ Senior researcher, Urban Agriculture Division, National Institute of Horticultural \& Herbal Science, RDA, Wanju 55365, South Korea \\ ${ }^{3}$ Postdoctoral researcherUrban Agriculture Division, National Institute of Horticultural \& Herbal Science, RDA, Wanju 55365, South Korea
}

\section{ABSTRACT}

Background and objective: This study was conducted to understand urban residents' perception of indoor plants in order to assist in the preparation of guidelines for growing plants indoors.

Methods: Questionnaires were distributed to urban residents currently growing plants or with experience of growing plants. The data of 247 respondents were subjected to analysis to assess their level of interest and ability with regard to growing plants, and their recognition of the selection and function of plants.

Results: Respondents showed high interest in growing plants at a level of 6.77 , but their ability was moderate. This suggests that information regarding plant maintenance should be provided to urban residents. They recognized the function of plants for improving the environment as important, and expected that indoor plants would improve their mood and visual experience. Satisfaction with growing plants was high from an emotional perspective. They recognized that the function of air purification function was important even if the actual performance or effect was not great. This indicates that the function of air purification should be emphasized more. As the result of the IPA, plants should be selected in consideration of morphological characteristics such as leaf, flower and fruit, and continuously managed to maintain their characteristics. Since the performance of pots was less satisfactory compared to their importance, they should be selected so that they harmonize better with plants and are of the appropriate size to fit the space. The type of plants is an important factor in plant selection in order to perform an environmental function, and the flower color and pot size are important in terms of aesthetics and healing.

Conclusion: When horticulture information on indoor plants is provided to urban residents, first, it should be provided to satisfy the functions of the plants required by urban residents and in order to promote and maintain the proper growth of plants. Second, various contents that utilize components should be developed to achieve plant function so that resident can determine the function of plants and select the type, quantity, and shape of plants to achieve the desired function.

Keywords: growing plants, importance-performance analysis, morphological characteristics, plants functions

\section{Introduction}

The amount of time urban residents spend indoors has been increasing, and the Ministry of Environment reported that Koreans spend more than 21 hours indoors per day, although it may depend on occupation, gender, and age (Ministry of Environment. 2010). In particular, in order to prevent the spread of viruses such as the recent Corona 19 , the indoor-stay time has increased, and is expected to increase further (Hankook Research. 2020). The indoor space is an important place as the time spent engaged in indoor activities such as people's daily life, work, and leisure pursuits increases. Recently, with the spread of pollutants including fine dust, people are increasingly aware of

\footnotetext{
This paper was funded by the research project of Rural Development Administration (PJ014270012020).

Received: October 9, 2020, Revised: November 13, 2020, Accepted: November 27, 2020

First author: Na Ra Jeong, Jnr202@korea.kr, (1) https://orcid.org/0000-0002-0235-1424

*Corresponding author: Na Ra Jeong, Jnr202@korea.kr, (1) https://orcid.org/0000-0002-0235-1424
} 
the importance of the indoor environment, and in particular, various researches and efforts to improve indoor air quality are continuously being conducted (Choi, 2020; Choi, 2019; Kim, 2018; Park et al., 2020). Social changes such as an increase in single-person households and the elderly population, and more time spent alone have undermined social support, ties, and communication, leading to various social problems such as loneliness and depression due to the resulting social isolation (Hwang et al., 2020; Kim, 2020; Nam, 2020). Under these circumstances, the interest in and demand for horticulture by people who want to derive psychological satisfaction through the emotional sympathy felt while growing plants has increased, and the new phrase "companion plant" has been coined (Koh, 2017; Kim, 2019).

In everyday life, people need directed attention to perform their functions efficiently, but their attention is often exhausted as their ability to pay oriented attention is limited and a lot of energy is used in various activities. Kaplan (1995) referred to the exhaustion of directed attention as mental fatigue. Directed attention can be recovered through rest, and several studies have found that mental fatigue is reduced and directed attention is restored in the process of perceiving and recognizing an environment similar to nature. The psychological effects of plants have been sufficiently recognized in culture, customs and empirical terms since long ago (Jo and Hong, 2016). As research findings have been published that show that direct or indirect contact with plants acts as a positive stimulus to help mental and physical recovery by reducing mental fatigue (Frumkin, 2001; Gullon, 2000; Lederbogen et al., 2011; Ulrich et al., 1991), interest in the psychological and physical effects of nature and plants has increased as a method to solve the problem of increased stress and disease in an artificial urban environment.

Plants introduced into indoor spaces are known to improve indoor comfort by controlling the thermal environment such as temperature and humidity, relieve stress such as tension and anxiety, and provide emotional stability (Son, 2002). As the time spent indoors increases, the introduction of indoor plants is on the increase for various purposes, such as controlling the indoor environment, creating a better atmosphere, providing a decorative effect, and improving psychological comfort (Lee et al., 2005). The indoor air purification and environmental control effects of plants have been attracting attention as a sustainable method since the Kyoto Protocol (1997). Oh and Jung (2012) explained that the change in $\mathrm{CO}_{2}$ concentration can be controlled according to the arrangement of indoor plants, and Schmitz et al. (2000) conducted a study on the absorption and metabolism of formaldehyde by indoor plants. In addition, plants affect temperature and humidity through transpiration, and are also involved in air purification through gas exchange (K.C. Son et al., 2000). Recently, studies have been published to prove that indoor plants are effective in reducing fine dust (Gawrońska and Bakera, 2015; Kwon, 2018). Many studies have been conducted in the field of horticultural therapy to investigate the psychological effects of indoor plants. Regarding such psychological function, a study was also conducted to analyze stress response by measuring physiological and psychological indicators according to the type and presence of plants (Son et al., 1977; Song, 2004). When people do gardening activities, they feel a sense of accomplishment and joy, and through these experiences, their confidence and self-esteem are improved (Lee, 2017; Park, 2018; Son, 2015). It was reported that, in the process of growing plants, people have an expectation and affection for such creatures, as well as a sense of responsibility for them, thereby reducing tension and anxiety while feeling psychological stability and flexibility through the green quality of the plants (Kim, 2019). Kim et al. (2019) also explained that modern people raise plants indoors to create a pleasant environment while satisfying their preference for plants, which increases their interest in the quality of life and their satisfaction with life. According to a report by Kim (2019), growing companion plants improved confidence and sociality, and relieved anxiety and tension, and thereby helped promote positive thinking. Several studies have found that contact with plants provides emotional stability to people and is effective in maintaining a positive mental state.

Many studies have been conducted not only on the role of indoor plants in improving the environment, but also on the positive psychological effects experienced by users. However, practical researches on the introduction and maintenance of indoor plants have been lacking. Therefore, this study surveyed the perception of indoor plants for ur- 
ban residents interested in introducing plants indoors, and based on this, aimed to provide basic data necessary for service providers engaged in indoor plant related industries to develop and utilize contents for introducing and managing indoor plants for urban residents.

\section{Research Methods}

\section{Subjects and survey methods}

A survey was conducted for urban residents in order to understand perceptions about introducing plants into the indoor space. Since it was expected that urban residents who attended fairs related to urban agriculture and gardens would be more interested in plants, gardening, and gardens than the general public, participants in garden fairs or urban agricultural fairs were surveyed; questionnaires were distributed to urban residents who were growing plants or had experience in growing plants among the visitors at the Busan Urban Agriculture Expo 2019 and 2019 Korea Urban Agriculture Expo 2019. Among the total 260 questionnaires answered, 247 were analyzed - excluding those that contained poor responses. After distributing the questionnaires, the respondents themselves were asked to fill out the questionnaires to minimize the influence of the surveyor. Among the respondents, the proportion of women was high with $68.8 \%$ being women and $31.2 \%$ being men; and with $37.2 \%$ of those who replied being in their 50 s and $33.2 \%$ in their $60 \mathrm{~s}$, the proportion of those in their $50 \mathrm{~s}$ or older was over $70 \%$ (Table 1 ).

Table 1. Characteristics of respondent

\begin{tabular}{|c|c|c|c|}
\hline \multicolumn{2}{|c|}{ Category } & \multirow{2}{*}{$\begin{array}{c}\text { Frequency } \\
77\end{array}$} & \multirow{2}{*}{$\begin{array}{c}\% \\
31.2\end{array}$} \\
\hline$C_{0}$ & Male & & \\
\hline Gender & Female & 170 & 68.8 \\
\hline \multirow{6}{*}{ Ages } & $20 \mathrm{~s}$ & 4 & 1.6 \\
\hline & $30 \mathrm{~s}$ & 19 & 7.7 \\
\hline & $40 \mathrm{~s}$ & 20 & 8.1 \\
\hline & $50 \mathrm{~s}$ & 92 & 37.2 \\
\hline & $60 \mathrm{~s}$ & 82 & 33.2 \\
\hline & 70 s over & 30 & 12.1 \\
\hline \multicolumn{2}{|c|}{ Total } & 247 & 100.0 \\
\hline
\end{tabular}

\section{Measurement tools}

The questions to determine the perception of urban residents on the introduction of indoor plants included the interest in growing plants (2 items); the function of plants (7 items); and the questions on plant selection (11 items). Their preference and interest in introducing indoor plants were surveyed using an 11-point scale $(0=$ No, $10=$ Very yes) for their interest and ability to grow plants. The functions of indoor plants were classified into 7 categories in terms of the environment, aesthetics, and healing, and the importance and performance were measured on a 5-point Likert scale $(1=$ Strongly disagree, $5=$ Strongly agree $)$. The importance and performance belonged to the same items, but the questions asked the respondents to answer regarding differences in perception before and after their experience. Factors to be considered for the introduction of indoor plants were classified into plants and planters (pots). In detail, plants were subdivided into type, number, shape, flower color, leaf color, size, etc.; planters were subdivided into size, type of finishing material, shape, location, and space scale. The importance and performance of each factor were measured on a 5-point Likert scale. To determine the internal consistency of the questions, a preliminary survey was conducted for horticultural and landscape science majors, and the questions were revised so that the Cronbach's alpha value for each items was 0.9 or higher (Table 2).

\section{Methods of data analysis}

The collected data were statistically analyzed using the SPSS 25 package program. Statistical analysis was conducted at a significance level of $5 \%$. The importance and performance of plant function, and the importance and performance of each factor for plant management were analyzed by t-test and ANOVA to test the significance according to demographic attributes such as gender and age group. If the nomality assumption was violated in the analysis of variance (ANOVA), the Kruskal-Wallis test, a nonparametric test, was performed. A t-test was performed to determine the relationship between importance and performance, and after analyzing the correlation between the items, Importance-Performance Analysis (IPA) was conducted. 
Table 2. Questionnaire composition and reliability analysis

\begin{tabular}{|c|c|c|c|}
\hline Questionnaire & Sub-Questionnaire & Scale & Cronbach' $\alpha$ \\
\hline \multirow{2}{*}{ Grow plants } & Interest to grow plants & 11 likert scale & - \\
\hline & Ability to grow plants & 11 likert scale & - \\
\hline $\begin{array}{l}\text { Plants function } \\
\text { importance }\end{array}$ & $\begin{array}{l}\text { Purification of indoor air, Atmosphere of space, Point of space, Plant fragrance, Interception } \\
\text { of electromagnetic waves, Peace of mind, Reduced eye strain }\end{array}$ & 5 likert scale & .939 \\
\hline $\begin{array}{l}\text { Plants function } \\
\text { performance }\end{array}$ & $\begin{array}{l}\text { Purification of indoor air, Atmosphere of space, Point of space, Plant fragrance, Interception } \\
\text { of electromagnetic waves, Peace of mind, Reduced eye strain }\end{array}$ & 5 likert scale & .917 \\
\hline $\begin{array}{l}\text { Plants } \\
\text { importance }\end{array}$ & $\begin{array}{l}\text { Kind of plants, Number of plants, Shape of plants, Flower color, Shape of leafs, Size of } \\
\text { plants, Type of pot, Size of pot, Shape/color of pot, Location of pot, Size of placement }\end{array}$ & 5 likert scale & .948 \\
\hline $\begin{array}{l}\text { Plants } \\
\text { performance }\end{array}$ & $\begin{array}{l}\text { Kind of plants, Number of plants, Shape of plants, Flower color, Shape of leafs, Size of } \\
\text { plants, Type of pot, Size of pot, Shape/color of pot, Location of pot, Size of placement }\end{array}$ & 5 likert scale & .933 \\
\hline
\end{tabular}

IPA technique is a simple and effective analysis method that can greatly help managers to identify priorities for improvements based on user's direct evaluation of attributes (Hansen and Bush, 1999; Deng, 2007). In this technique, the importance and performance of the evaluation elements are measured and the measured values are plotted on a two-dimensional chart having four quadrants; a meaning is given according to the position; the main attributes of the importance and performance fall into the four quadrants; and then they are compared and analyzed with such relative values (Lee and Lee, 2013). The quadrants are divided with the average values of performance on the x-axis and those of importance on the y-axis, and the priority is determined through the coordinates where each variable value is displayed (Lee, 2010). The meanings of the importance-performance matrix is shown in Fig. 1. Above all, since it allows us to identify priorities that need improvement and find areas of excess or shortcomings (Matzler et al., 2004), industry managers involved in the use of indoor plants are able to establish strategies to improve the satisfaction of urban residents in introducing indoor plants based on these derived results. In order to analyze the selection factors according to the functional types of indoor plants, a linear regression analysis was performed with the function of indoor plants as a dependent variable and the importance of plant selection factors as an independent variable.

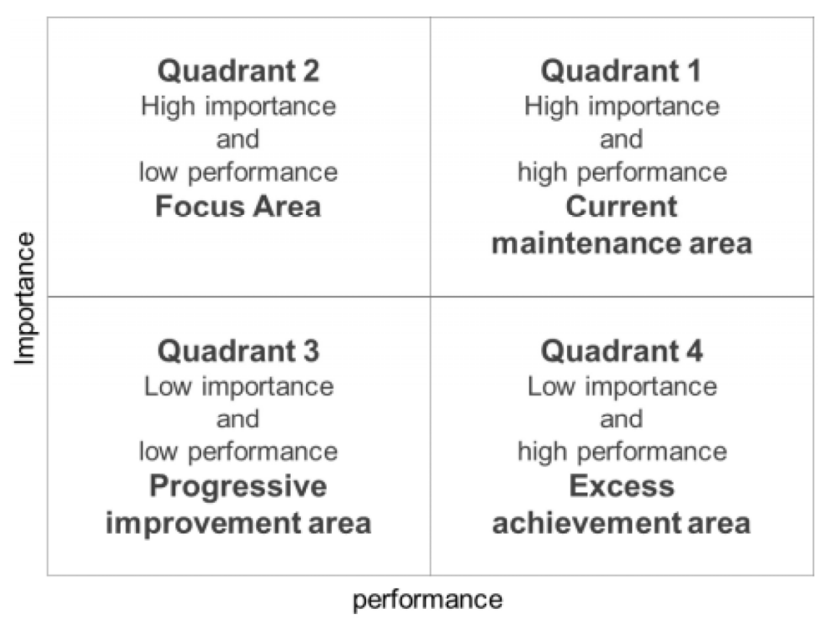

Fig. 1. IPA Importance-performance matrix

\section{Results and Discussion}

\section{Interest and ability in growing indoor plants}

The interest in growing indoor plants was above average with an average of 6.77 out of 10; and the interest of females was relatively higher than the interest of males, and the level of interest among those in their 40-50st was higher than that of other ages, but there was no statistically significant difference between them. The ability to grow plants averaged 5.96, which was slightly higher than the normal level; there was little difference in the ability to grow plants according to sex and age (Table 3). Compared to their interest in growing plants, the evaluation score for their ability was lower. This means that when urban residents directly purchase or grow plants, information on plant character- 
Table 3. Interest and ability to grow indoor plants

\begin{tabular}{|c|c|c|c|c|c|c|c|c|}
\hline \multirow{2}{*}{ Division } & \multirow{2}{*}{ Mean } & \multicolumn{3}{|c|}{ Gender } & \multicolumn{4}{|c|}{ Ages } \\
\hline & & Male & Female & $\mathrm{t}$ & $2-30 \mathrm{~s}$ & $4-50 \mathrm{~s}$ & 60 s over & $\mathrm{F}$ \\
\hline Interest to grow plants & $6.77 \pm 3.3$ & 6.62 & 7.02 & $-0.737^{\mathrm{NS}}$ & 6.06 & 7.24 & 6.40 & $1.849^{\mathrm{NS}}$ \\
\hline Ability to grow plants & $5.96 \pm 1.9$ & 6.04 & 6.13 & $-0.278^{\mathrm{NS}}$ & 5.19 & 6.06 & 6.11 & $1.638^{\mathrm{NS}}$ \\
\hline
\end{tabular}

${ }^{\mathrm{NS}}$ Non-significant.

istics and growth environment should be provided. A preceding study (Jeong et al., 2017) also found that the necessity of and participation in education on raising plants and garden management were high. In order to help urban residents grow plants on a daily basis, it is necessary to develop and operate programs such as continuous education and provide contents on plant growing.

\section{Analysis of importance and performance of indoor plant functions}

As a result of analyzing the importance of indoor plant functions on a 5-point Likert scale, atmosphere of space and mental stability were recognized as the most important functions with 3.97 points, which were followed by focal point of space (3.92), reduced eye strain (3.89), and indoor air purification (3.88). It was found that urban residents place importance on improving the ambience and environment of the space, as well as making their mind and eyes relaxed, by introducing indoor plants.. Along with the recent trend of "planterier" and "greenterier" (Lee, 2019), which were coined through a combination of interior decorating and the introduction of indoor plants, it seems that urban residents' awareness of using plants to decorate indoor spaces and create ambience has increased. On the other hand, the importance of the function of plants which is known to include the blocking of electromagnetic waves indoors, was considered relatively the lowest; and the importance of indoor air purification such as reducing fine dust, which is a recent issue, was considered high. Although the functions that plants can provide in indoor spaces are diverse, the importance of plants is considered to be relatively different depending on the issues and cultural circumstances prevailing at any particular time. As for the performance of indoor plant functions, peace of mind was the highest with 4.29 , which was followed by atmosphere of space (4.22), reduced eye strain (4.13), focal point of space (4.11), plant fragrance (4.05), indoor air purification (4.01), and electromagnetic wave blocking (3.85). Overall, the performance of indoor plant functions was high with with a score of more than 4 points (on the scale).

When analyzing the difference between the importance and performance of indoor plant functions, performance was generally evaluated high, and all those functions except for indoor air purification showed a statistically significant difference (Table 4). The functions with the greatest difference between importance and performance included mental stability, reduced eye strain, and atmosphere of space; and indoor air purification shows the least difference. Analyzing the differences according to gender, the importance of air purification was highest for men, but the actual performance was highest in mental stability. The difference between importance and performance for men was statistically significant (Table 4), but the difference for women was not. In other words, compared to females, males usually do not perceive plants as important, but they are more likely to experience the importance of plants while actually growing them.

Analyzing these data with the Importance-Performance Analysis (IPA) matrix, based on the reference value of 3.78 for importance (Y-axis) and 4.15 for performance (X-axis), the distribution of the scores is plotted as a four quadrant matrix as shown in Fig. 2. The functions that required continuous efforts to maintain the function with high importance and high performance in Quadrant 1 were atmosphere of space, focal point of space, mental stability, and eye fatigue reduction; plants should be introduced to and managed in indoor space so that indoor plants can adjust the atmosphere of the space and become a focal point, and provide emotional and physical satisfaction through this. The function of high importance and low performance was indoor air purification; first of all, in order to make this 
Table 4. Analysis of the importance and performance of indoor plant functions

\begin{tabular}{|c|c|c|c|c|c|c|c|}
\hline & \multirow{2}{*}{ division } & \multicolumn{2}{|c|}{ Importance } & \multicolumn{2}{|c|}{ Performance } & \multirow{2}{*}{ I-P } & \multirow{2}{*}{ t-test } \\
\hline & & mean $(\mathrm{I})$ & SD & $\operatorname{mean}(\mathrm{P})$ & SD & & \\
\hline \multirow{7}{*}{ All } & Purification of indoor air & 3.88 & 0.976 & 4.01 & 0.923 & -0.095 & -1.343 \\
\hline & Atmosphere of space & 3.97 & 0.990 & 4.22 & 0.817 & -0.232 & $-3.089 * *$ \\
\hline & Point of space & 3.92 & 0.970 & 4.11 & 0.874 & -0.198 & $-2.521 *$ \\
\hline & Plant fragrance & 3.79 & 1.030 & 4.05 & 0.985 & -0.218 & $-2.477^{*}$ \\
\hline & Interception of electromagnetic waves & 3.64 & 1.059 & 3.85 & 1.045 & -0.200 & $-2.641 * *$ \\
\hline & Peace of mind & 3.97 & 1.039 & 4.29 & 0.824 & -0.300 & $-3.717 * *$ \\
\hline & Reduced eye strain & 3.89 & 1.041 & 4.16 & 0.885 & -0.240 & $-3.429 * *$ \\
\hline \multirow{7}{*}{ Male } & Purification of indoor air & 3.68 & 0.997 & 4.03 & 0.768 & -0.350 & $-2.211^{*}$ \\
\hline & Atmosphere of space & 3.71 & 1.055 & 4.29 & 0.642 & -0.585 & $-3.750 * *$ \\
\hline & Point of space & 3.54 & 1.097 & 4.18 & 0.683 & -0.641 & $-3.953 * *$ \\
\hline & Plant fragrance & 3.46 & 0.989 & 4.14 & 1.004 & -0.676 & $-2.790 * *$ \\
\hline & Interception of electromagnetic waves & 3.19 & 1.126 & 3.70 & 1.151 & -0.514 & $-2.618^{*}$ \\
\hline & Peace of mind & 3.45 & 1.176 & 4.43 & 0.636 & -0.975 & $-5.194 * *$ \\
\hline & Reduced eye strain & 3.60 & 1.057 & 4.18 & 0.747 & -0.575 & $-3.514 * *$ \\
\hline \multirow{7}{*}{ Female } & Purification of indoor air & 3.89 & 0.999 & 3.96 & 0.970 & -0.067 & -0.669 \\
\hline & Atmosphere of space & 4.04 & 0.969 & 4.24 & 0.895 & -0.200 & -1.827 \\
\hline & Point of space & 4.02 & 0.897 & 4.19 & 0.862 & -0.168 & -1.668 \\
\hline & Plant fragrance & 3.87 & 1.075 & 3.90 & 1.038 & -0.037 & -0.309 \\
\hline & Interception of electromagnetic waves & 3.69 & 1.080 & 3.78 & 1.095 & -0.082 & -0.818 \\
\hline & Peace of mind & 4.19 & 0.969 & 4.36 & 0.847 & -0.170 & -1.446 \\
\hline & Reduced eye strain & 3.98 & 1.034 & 4.13 & 0.950 & -0.149 & -1.436 \\
\hline
\end{tabular}

${ }^{*} p<.05, \stackrel{* *}{p}<.01$.

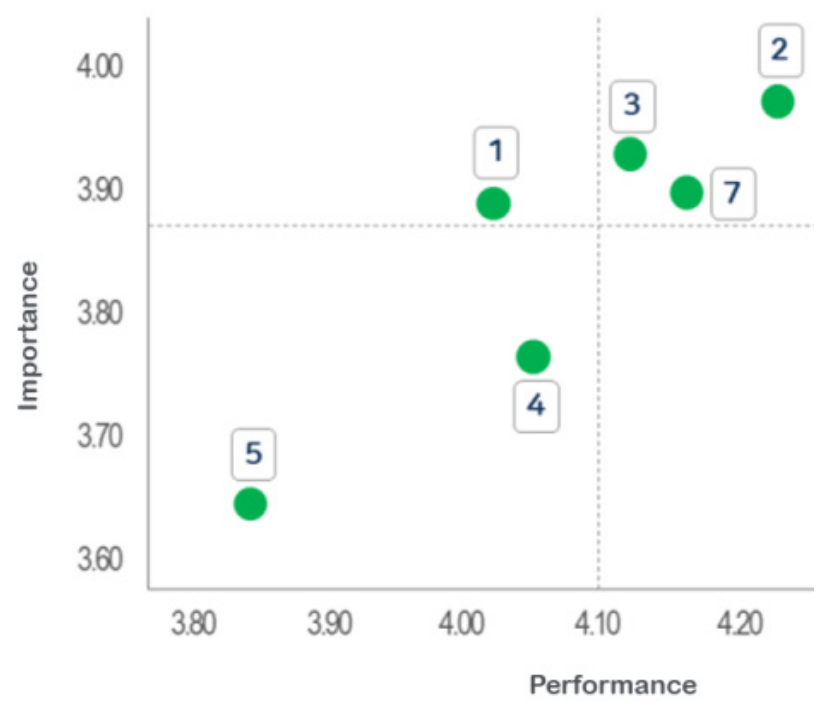

Fig. 2. The importance and performance matrix for plants function. 1 = Purification of indoor air, 2 = Atmosphere of space, 3 = Point of space, 4 = Plant fragrance, 5 = Interception of electromagnetic waves, 6 = Peace of mind, 7 = Reduced eye strain. function work well, appropriate information should be provided and managed to change the type of plants or to make the air purification mechanism of plants work well. The functions of low importance and low performance are plant fragrance and blocking electromagnetic waves. Since these two functions are less important than in the past regarding the introduction of indoor plants, it would be desirable to consider them after achieving other functions.

\section{Analysis of importance and performance of indoor plant selection factors}

When analyzing the importance of each factor for the introduction of indoor plants, the importance of plant factors is slightly higher than the normal level, with slightly less than 4 out of 5 points. When analyzed by factors, the importance of the unique characteristics of plants was high in the order of type of plant $(3.84)$, plant color $(3,82)$, and 
leaf color and shape (3.79). The importance of pot factors was higher for the space in the order of the size (3.91) and location (3.83) of the space in which a pot would be placed. When introducing and managing plants indoors, the properties of plants and the selection of pots are determined to be important. The performance of indoor plant selection factors was high in terms of flower color, and leaf color and shape, but relatively low in terms of plant shape. The location and size of the space where plants would be placed showed high performance, but the size and shape of the finishing material showed relatively low performance. Arrangement of pots can be decided according to the individual's preference, but if plants are not directly purchased but obtained indirectly which leaves no choice for him/her, the performance is considered to be slightly low.

When comparing the importance and performance of indoor plant selection factors, the performance was higher than the importance in all factors, which showed a statistically significant difference (Table 5). The number of plants, color of flowers, shape and color of leaves had a large

Table 5. Analysis of the importance and performance of choosing indoor plants

\begin{tabular}{|c|c|c|c|c|c|c|c|}
\hline & \multirow{2}{*}{ division } & \multicolumn{2}{|c|}{ Importance } & \multicolumn{2}{|c|}{ Performance } & \multirow{2}{*}{$\mathrm{I}-\mathrm{P}$} & \multirow{2}{*}{ t-test } \\
\hline & & mean $(\mathrm{I})$ & $\mathrm{SD}$ & mean $(\mathrm{P})$ & $\mathrm{SD}$ & & \\
\hline \multirow{11}{*}{ All } & Kind of plants & 3.84 & .929 & 4.03 & .891 & -0.203 & $-2.505^{*}$ \\
\hline & Number of plants & 3.60 & 1.019 & 4.00 & .998 & -0.416 & $-4.904 * *$ \\
\hline & Shape of plants & 3.73 & .906 & 3.92 & .848 & -0.247 & $-2.922 * *$ \\
\hline & Flower color & 3.83 & .962 & 4.07 & .837 & -0.304 & $-3.792 * *$ \\
\hline & Shape of leafs & 3.79 & .903 & 4.02 & .787 & -0.266 & $-3.663^{* *}$ \\
\hline & Size of plants & 3.77 & .940 & 3.92 & .866 & -0.196 & $-2.467 *$ \\
\hline & Type of pot & 3.69 & 1.0218 & 3.98 & .930 & -0.297 & $-3.808 * *$ \\
\hline & Size of pot & 3.79 & .937 & 3.88 & .902 & -0.161 & $-2.049^{*}$ \\
\hline & Shape/color of pot & 3.68 & .963 & 3.89 & .936 & -0.251 & $-3.390 * *$ \\
\hline & Location of pot & 3.83 & .907 & 4.07 & .880 & -0.268 & $-3.451 * *$ \\
\hline & Size of placement & 3.91 & .936 & 4.01 & .881 & -0.127 & -1.403 \\
\hline \multirow{11}{*}{ Male } & Kind of plants & 3.53 & 1.062 & 4.05 & 0.846 & -0.525 & $-3.058 * *$ \\
\hline & Number of plants & 3.53 & 1.037 & 3.98 & 1.025 & -0.450 & $-2.516^{*}$ \\
\hline & Shape of plants & 3.59 & 0.880 & 3.97 & 0.903 & -0.385 & -1.892 \\
\hline & Flower color & 3.58 & 1.010 & 4.13 & 0.883 & -0.550 & $-2.905^{* *}$ \\
\hline & Shape of leafs & 3.60 & 0.810 & 4.05 & 0.783 & -0.450 & $-2.746^{* *}$ \\
\hline & Size of plants & 3.43 & 0.931 & 3.98 & 0.832 & -0.550 & $-3.439 * *$ \\
\hline & Type of pot & 3.39 & 1.001 & 4.00 & 0.986 & -0.605 & $-3.541 * *$ \\
\hline & Size of pot & 3.55 & 1.037 & 3.93 & 0.997 & -0.375 & $-2.360 *$ \\
\hline & Shape/color of pot & 3.35 & 1.027 & 3.68 & 1.071 & -0.325 & -1.918 \\
\hline & Location of pot & 3.65 & 0.949 & 4.13 & 0.822 & -0.475 & $-2.423^{*}$ \\
\hline & Size of placement & 3.74 & 1.044 & 4.05 & 0.887 & -0.308 & -1.374 \\
\hline \multirow{11}{*}{ Female } & Kind of plants & 3.86 & 0.883 & 4.10 & 0.921 & -0.244 & $-2.048 *$ \\
\hline & Number of plants & 3.55 & 1.057 & 4.04 & 0.911 & -0.488 & $-4.016^{* *}$ \\
\hline & Shape of plants & 3.73 & 0.905 & 4.00 & 0.787 & -0.271 & $-2.349^{*}$ \\
\hline & Flower color & 3.95 & 0.888 & 4.15 & 0.788 & -0.195 & -1.687 \\
\hline & Shape of leafs & 3.88 & 0.916 & 4.06 & 0.817 & -0.181 & -1.624 \\
\hline & Size of plants & 3.91 & 0.942 & 3.95 & 0.856 & -0.045 & -0.376 \\
\hline & Type of pot & 3.72 & 1.046 & 3.90 & 0.911 & -0.183 & -1.587 \\
\hline & Size of pot & 3.89 & 0.930 & 3.98 & 0.846 & -0.085 & -0.716 \\
\hline & Shape/color of pot & 3.78 & 1.016 & 3.99 & 0.893 & -0.212 & -1.950 \\
\hline & Location of pot & 3.86 & 0.930 & 4.05 & 0.951 & -0.184 & -1.552 \\
\hline & Size of placement & 4.01 & 0.932 & 3.98 & 0.926 & 0.035 & 0.249 \\
\hline
\end{tabular}


difference in importance and performance, whereas the size of plants and the size of pots did not differ significantly. In the ranking of importance, the type of plant was high, but in the ranking of performance, the color of plants was high. Except for these, there was no significant difference in the ranking of importance and performance. There was a statistically significant difference between importance and performance in males, while there was no statistically significant difference between those among females except for the type, number, and shape of plants (Table 5). On the whole, men showed a high level of satisfaction after growing plants, so it is considered important that men should have the opportunity to grow plants.

When analyzed by the IPA matrix, based on the reference value of 3.88 for importance (Y-axis) and 4.10 for performance (X-axis), the distribution of the scores is plotted as a four quadrant matrix as shown in Fig. 3. According to the IPA matrix, the factors that should be continuously considered to maintain the function with high importance and high performance are the type of plant, the color of the flower, the color and shape of the leaves, the location of the plant, and the size of the space the plant will be placed in. A previous study (Lee, 2020) also stated that the preference of plant shape and leaf color influenced visual perception preference. In order to increase the perform-

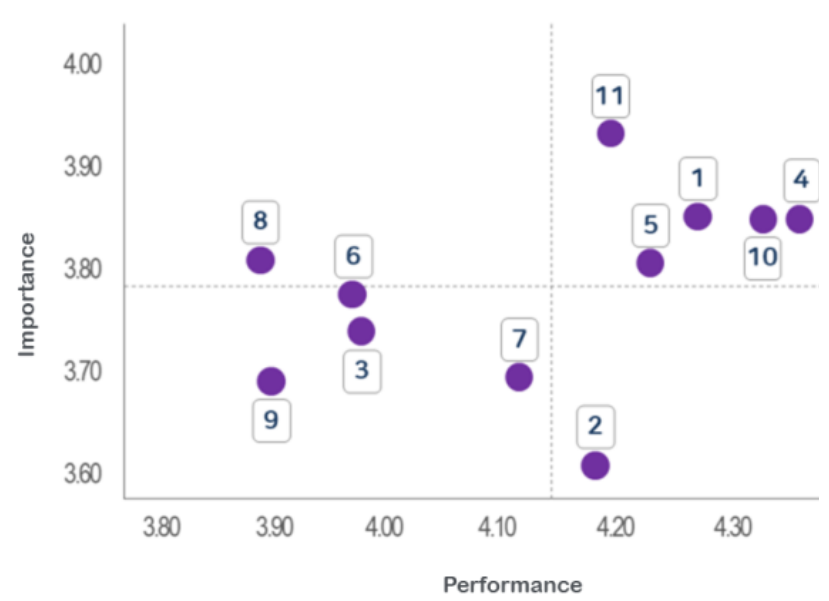

Fig. 3. The importance and performance matrix for choosing indoor plants. 1 = Kind of plants, 2 = Number of plants, 3 = Shape of plants, $4=$ Flower color, $5=$ Shape of leafs, 6 = Size of plants, $7=$ Type of pot, $8=$ Size of pot, 9 = Shape/color of pot, $10=$ Location of pot, $11=$ Size of placement. ance of indoor plant selection factors, the type and morphological characteristics of plants, as well as the appropriate location to be placed, should be continuously managed. Since the function factor with high importance and low performance is the size of plants and the size of pots to contain plants, it is required to plant plants in the size of the pot that fits the size of the space and arrangement conditions when introducing plants indoors. In addition, since plants grow continuously and their size increases, proper pruning and replanting should be conducted to maintain a constant growth state. To this end, service providers will be able to provide information by developing media content using video for plant maintenance. Furthermore, it will be possible to build a platform that can solve user problems through methods such as real-time video information and remote management to provide support from plant sales to management. Factors with low importance and low performance are the shape of plants, the material, shape, and color of pots. Factors with low importance and high performance factor, which is an area where excessive effort should be avoided, is the number of plants, so when introducing indoor plants, the achievement of function should be focused on rather than the number of plants. To this end, when providing services involved in the introduction of indoor plants, with the priority goal of achieving the functions of plants required by urban residents, services that help plants be maintained in the best condition should be provided.

\section{Analysis of selection factors by indoor plant function type}

By classifying indoor plant functions into environmental, aesthetic, and healing aspects, we tried to grasp the importance of the factors to be selected according to each function when selecting plants. For this, a linear regression analysis was conducted with the importance of plant function as the dependent variable and the importance of plant selection factors as the independent variable. Among the functions of plants, important selection factors in terms of environment were the type of plant, the shape and color of pots, and the shape of leaves. The explanatory power of this model was $42.5 \%$, and the most important selection 
factor for the environmental function of the plant was the type of plants. When selecting a plant to achieve an aesthetic function, the color of flowers, the size of pots, and the type of plants were the selection factors and the explanatory power was $36.5 \%$ (Table 6). In terms of healing, the color of flowers, size of pots, and the number of plants were selection factors, and the explanatory power was $48.5 \%$. To achieve the environmental functions such as indoor air purification, a priority to be considered is the selection of suitable plants for environmental improvement. In terms of aesthetics, the color of flowers is an important factor that enables plants to decorate indoor spaces comfortably and improve the atmosphere. For the healing function of plants, the number of plants along with the color of flowers is an important selection factor. In other words, the color of flowers and the size of pots are important selection factors in both aesthetic and healing aspects when introducing indoor plants, and the number of plants is important for achieving a healing function in an indoor space. When introducing plants indoors, priority consideration should be given to the benefits that can be obtained through plants, and then the type, shape, and color of plants and pots should be selected to achieve these functions. A previous study (Jang et al., 2018) reported that emotional relaxation is important as well as environmental and aesthetic aspects in the function of indoor plants, and particularly, preference for plants which help increase emotional relaxation and natural healing power is high. That is, in introducing plants indoors, it is necessary to provide contents for management along with components such as plant materials and pots to achieve environmental, aesthetic, and healing functions.

\section{Conclusion}

This study surveyed urban residents' perception of indoor plants in order to provide basic data necessary for introducing plants into indoor spaces and providing services for their management. To this end, 247 urban residents were surveyed regarding their perception of the importance and performance of plant functions and plant selection factors. They had more than a normal level of interest in growing plants in residential spaces, but their ability to grow plants was only moderate. Since people's interest in the introduction and cultivation of indoor plants has increased, and their demand for companion plants due to the Corona 19 pandemic is rising, but their ability to directly grow plants is insufficient, various methods for sharing and providing methods or information for plant cultivation and management are required to be sought in terms of providing horticultural services. Research on methods and technologies

Table 6. Regression analysis to identify selection factors affecting indoor plant function

\begin{tabular}{|c|c|c|c|c|c|c|c|}
\hline $\begin{array}{l}\text { Type of } \\
\text { function }\end{array}$ & Factor & $\begin{array}{l}\text { Unstandardized } \\
\text { coefficients }\end{array}$ & $\begin{array}{c}\text { Standard } \\
\text { error }\end{array}$ & $\begin{array}{l}\text { Standardized } \\
\text { coefficients }\end{array}$ & $\mathrm{t}$ & $\mathrm{F}$ & adjusted $\mathrm{R}^{2}$ \\
\hline \multirow{4}{*}{$\begin{array}{c}\text { Environment } \\
\text { al aspect }\end{array}$} & constant & 0.998 & 0.281 & & $3.552 * *$ & \multirow{4}{*}{$36.742 * *$} & \multirow{4}{*}{0.425} \\
\hline & Kind of plants & 0.285 & 0.080 & 0.301 & $3.591 * *$ & & \\
\hline & Shape/color of pot & 0.258 & 0.079 & 0.270 & $3.251^{* *}$ & & \\
\hline & Shape of leafs & 0.207 & 0.090 & 0.202 & $2.288^{*}$ & & \\
\hline \multirow{4}{*}{$\begin{array}{l}\text { Aesthetic } \\
\text { aspect }\end{array}$} & constant & 1.358 & 0.288 & & $4.715^{* *}$ & \multirow{4}{*}{$29.151 * *$} & \multirow{4}{*}{0.365} \\
\hline & Flower color & 0.255 & 0.098 & 0.260 & $2.605^{* *}$ & & \\
\hline & Size of pot & 0.244 & 0.087 & 0.253 & $2.804^{* *}$ & & \\
\hline & Kind of plants & 0.187 & 0.094 & 0.188 & $1.987^{*}$ & & \\
\hline \multirow{4}{*}{$\begin{array}{l}\text { Healing } \\
\text { aspect }\end{array}$} & constant & 0.698 & 0.277 & & 2.521 & \multirow{4}{*}{$44.960 * *$} & \multirow{4}{*}{0.485} \\
\hline & Flower color & 0.327 & 0.086 & 0.311 & $3.787 * *$ & & \\
\hline & Size of pot & 0.292 & 0.085 & 0.288 & $3.446^{* *}$ & & \\
\hline & Number of plants & 0.212 & 0.073 & 0.217 & $2.890^{*}$ & & \\
\hline
\end{tabular}

${ }^{*} p<.05,{ }^{* *} p<.01$. 
for providing services in a virtual space using AI, ICT, etc. due to the 4th Industrial Revolution and the Corona 19 pandemic should also be conducted. After setting the direction of introduction and management of plants in consideration of the function of plants, plants should be selected to function to adjust the atmosphere of space and promote mental and physical stability. As the indoor air purification function was not high in performance compared to its importance, continuous management such as changing the type of plants or washing the leaves should be carried out to improve the air purification effect of indoor plants. When providing horticultural services, the type of plants is an important selection factor in order to achieve the environmental function of plants, and the color of flowers and the size of pots are important ones in terms of aesthetics and healing. In the introduction of indoor plants, it is necessary to grasp the functions of plants required by urban residents, and to support them to select the type, quantity, and form of plants that can achieve such functions.

In the case of providing horticultural services to urban residents using indoor plants, first, information on plants that can meet the functions of plants required by urban residents should be provided, as well as information to maintain appropriate growth conditions. Second, it is required to develop various information contents to utilize the components to achieve the function of the plant. Third, educational programs should be operated that can enhance the understanding of growing plants indoors, including contents that provide information on directly growing and using plants, Lastly, a platform that can provide services in real time should be built, using big data, AI, and ICT, which are components of the 4th industrial revolution.

However, this study is the result of a research initiative targeting urban residents who have experience growing plants, so it has limitations in that it cannot represent the entire urban population. In the future, research initiatives that include urban residents who are not interested in growing plants as subjects should be continued, as well as research to suggest plants that can be applied according to the function of plants and the selection factors.

\section{References}

Choi, H.J. 2020. National policy for management of indoor air quality. Korean Ind. Chem. News. 23(4):30-36.

Choi. M.S. 2019. A study on the perception level and proper management of indoor air quality recognition in elderly care hospital workers. J. Korea Soc. Comput. Inf. 24(11):171-178. https://doi.org/10.9708/jksci.2019.24.11.171

Deng, W. 2007. Using a revised importance-performance analysis approach: The case of Taiwanese hot springs tourism. Tour. Manage. 28(5):1274-1284. https://doi.org/10.1016/j.tourman.2006.07.010

Frumkin, H. 2001. Beyond toxicity: Human health and the natural environment. Am. J. Prev. Med. 20(3): 234-240. https://doi.org/10.1016/S0749-3797(00)00317-2

Gawrońska, H. and B. Bakera. 2015. Phytoremediation of particulate matter from indoor air by Chlorophytum comosum L. plants. Air Qual. Atmos. Health 8(3):265-272. https://doi.org/10.1007/s11869-014-0285-4

Gullon, E. 2000. The biophilia hypothesis and life in the 21th century: Increasing mentalhealth orincreasing pathology?. J. Happiness Stud. 1(3):293-322. https://doi.org/ 10.1023/A:1010043827986

Hankook Research. 2020, June 1. The impact and prospects of consumer life and consumer activities in the covid-19. Hankook Research. Retrieved from https://www.hrc.co.kr /renewal/newsletter/data/wrn98.pdf

Hansen, E. and R.J. Bush. 1999. Understanding customer quality requirements: Model and application. Ind. Mark. Manage. 28(2):119-130. https://doi.org/10.1016/S00198501(98)00007-8

Hwang, Y.J., Y.Y. Nam, and H. Lee. 2020. Psychological implications of leisure experience at home alone : A self-determination perspective. J. Tour. Sci. 44(5):77-95. http://dx.doi.org/10.17086/JTS.2020.44.5.77.95

Jang, H.S., G.M. Gim, S.J. Jeong, and J.S. Kim. 2018. The importance of indoor foliage plants and human emotions to indoor foliage plants. J. People Plants Environ. 21(2):155-166. https://doi.org/10.11628/ksppe.2018.21.2.155

Jeong, N.R., M.I. Jeong, S.W. Han, and J.S. Kim. 2017. Study on community gardens for village development projects. J. People Plants Environ. 20(1):7-17. https://doi.org/10.11628/ksppe.2017.20.1.007 
Jo, H.J. and G.S. Hong. 2016. Visio-psychological effect of spring flowers blossoms on university students. J. Environ. Sci. Int. 25(8):1097-1105. https://doi.org/10.53 22/JESI.2016.25.8.1097

Kaplan, S. 1995. The restorative benefits of nature: Towards an integrative framework. J. Environ. Psychol. 15: 169-82.

Kim, A. 2020. The impact of social isolation on healthrelated quality of life of older adults living alone. J. Digit. Converg. 18(8):343-351. https://doi.org/10.14400/ JDC.2020.18.8.343

Kim, H.S. 2019. The effect of pet plants on the emotion of university students. Doctoral dissertation, Gangneung-Wonju National University, Gangneung, Korea.

Kim, S.W. 2018. Improvement plan of G-SEED for the indoor air quality management and occupant health due to the particulate. J. Korea Inst. Healthc. Archit. 24(4): 89-94.

Kim, Y.H., J.W. Hong, and J.Y. Kim. 2019. Life satisfaction and the perception of plants are increased by growing indoor plants. Flower Res. J. 27(1):42-50. https://doi.org/10.11623/frj.2019.27.1.07

Koh, E.H. 2017. Effect of ornamental plants on mental health of elderly people living alone in the viewpoint of companion plants. Doctoral dissertation, Sahmyook University, Seoul, Korea.

Kwon, K.J. 2018. Improving indoor environments and utilizing plant-microbial fuel cell according to environmental conditions in foliage plants. Doctoral dissertation, Chungbuk National University, Cheongju, Korea.

Lederbogen, F., P. Kirsch, L. Haddad, F. Streit, H. Tost, P. Schuch, W.S. Stefan, J.C. Pruessner, M. Rietschel, M. Deuschle, and A. Meyer-Lindenberg. 2011. City living and urban upbringing affect neural social stress processing in humans. Nature 474:498-501. https://doi.org/10.1038/nature10190

Lee, J.H., and J.S. Lee. 2013. A survey on competencies of teachers of guidance using IPA. J. Yeolin Educ. 21(3):53-76.

Lee, S.Y. 2010. A Study on the importance performance analysis of multi-cultural education programs in Seoul elementary schools. Master's thesis, Ewha Womans University, Seoul, Korea.

Lee, T.H. 2019, November 25. It's the age of pet plants. the spotlighted 'Planterior'. Kukminilbo. Retrieved from http://m.kmib.co.kr/view.asp?arcid=0924109481

Lee. S.H. 2017. Effects of university students' interest in horticultural activity on their psychological well-being and sociality development. Master's thesis, Daegu Catholic University, Daegu, Korea.

Lee, Y.S. 2020. A study on the psychological perception characteristics of air purifying plants according to visual perception preference. Des. Res. 5(3): 94-104. https://doi. org/10.46248/kidrs.2020.3.94

Matzler, K., F. Bailom, H.H. Hinterhuber, B. Renzl, and J. Pichler. 2004. The asymmetric relationship between attribute-level performance \& overall customer satisfaction: A reconsideration of the importance-performance analysis. Ind. Mark. Manage. 33(4):271-277. https://doi.org/10.1016/S0019-8501(03)00055-5

Ministry of Environment. 2010, Jan. 22. Evaluation of pollution exposure by daily life patterns for the first time in Korea. Sejong, Korea: Author. Retrieved from http://me.go.kr

Nam, E.W. 2020. Social prescribing: Overcome social isolation and depression of COVID-19 outbreak era. Korean J. Health Educ. Promot. 37(1):113-116. https://doi.org/10.14367/kjhep.2020.37.1.113

Oh, G.S. and G.J. Jung. 2012. A field study on improvement of indoor air quality, occupants' perceived air quality, sick building syndrome symptoms, and learning concentration with indoor plants in university classrooms. J. Archit. Inst. Korea Plan. Des. 28(7):261-268

Park, E.J. 2018. Effect of horticultural therapy on self-esteem and depression in disabled person. Doctoral dissertation, Mokpo National University, Mokpo, Korea.

Park, H.C., D.H. Lee, and J.J. Yee. 2020. A study on development and application of sequential control algorithm of ventilation and air cleaning system for improving indoor air quality in school classroom. J. Archit. Inst. Korea Struct. Constr. 36(5):187-194. https://doi.org/10.5659/J AIK_SC.2020.36.5.187

Schmitz H, U.T.E. Hilgers, and M. Weidner. 2000. Assimilation and metabolism of formaldehyde by leaves appear unlikely to be of value for indoor air purification. New Phytol. 147(2):307-316. https://doi.org/10.1046/j.1469-8 137.2000.00701.x

Son K.C. 2002. Horticultural therapy. Seoul, Korea: JAPub. 
Son, K.C., K.C. Kang, S.H. Lee, and M.H. Yoo. 1997. Evaluation of impression of indoor foliage plants and psychological effect of resident according to their arrangement. Hortic. Sci. Technol. Vol. 15 (Suppl. I): 501-502.

Son, K.C., S.H. Lee, S.G. Seo, and J.E. Song. 2000. Effects of foliage plants and potting soil on the absorption and adsorption of indoor air pollutants.J. Korean Soc. Hortic. Sci. 41(3):305-310

Son, M.R. 2015. Effect of horticultural therapy on school life adaptation and stress of juvenile. Doctoral dissertation, Wonkwang University, Iksan, Korea.

Song, J.E. 2004. Effect of interior plantscape in office on psycho-physiological improvement and stress alleviation of indoor workers. Doctoral dissertation, Konkuk University, Chungju, Korea.

Ulrich, R.S., R.F. Simon, B.D. Losito, E. Fiorito, M.A. Miles, and M. Zelson. 1991. Stress recovery during exposure to natural and urban environments. J. Environ. Psychol. 11(3): 201-230. 